http://dx.doi.org/10.4314/jae.v16i2.2

\title{
Health and Environmental Hazards Posed by Urban Livestock Keeping in Enugu Urban, Nigeria: Implication for Climate Change Mitigation
}

\author{
A.N. Asadu, E. M. Igbokwe, Chah, J.M. and Enwelu, I.A. \\ Department of Agricultural Extension \\ University of Nigeria Nsukka
}

\begin{abstract}
Livestock's contribution to climate change is now an established fact and closeness of livestock to human beings in urban areas portends many health and environmental implications. The study ascertained farmer's perception of health and environmental hazards posed by livestock keeping in Enugu Urban, Nigeria and its implication for climate change mitigation. Seventy five heads of households were freely characterized and data were obtained through interview. Data were analyzed using percentage and mean. Majority of the farmers kept improved chicken under intensive system. All the respondents were aware of health and environmental implications of livestock keeping in urban areas, though only few (4.0\%) indicated being aware that livestock could cause climate change. Other environmental issues identified by them included: destruction of crops (89.3\%) filth in urban areas (89.3\%); noise making (88.0\%). The health issues included spreading of diseases (50.7\%); causing of accidents (46.7\%); bad smell (86.7\%). The control measures as perceived by the respondents included proper disposal of waste $(M=1.79)$, seeking veterinary services $(M=1.85)$, cleaning shed regularly $(M=1.80)$ and provision of extension services $(M=1.85)$. It was recommended that urban agriculture should be integrated into urban health and environmental policies. Extension services should also raise awareness among urban livestock keepers of the impact of livestock on climate change and offer them useful advice on appropriate mitigation measures.
\end{abstract}

Keywords: livestock, urban environment, climate change, mitigation, Nigeria 


\section{Introduction}

The livestock sector has a primary and growing role in the agricultural economy. It is a major provider of livelihoods for the larger part of the world's poor. It is also an important determinant of human health and provides a component of diets (FAO, 2006). The global demand for animal product is increasing with growing urbanization and rising meat consumption especially in developing countries (Gerber and Steinfeld, 2008). This growth in demand for milk and meat is mainly driven by urban consumers in developing countries (Johnson, 2009). The demand is predicted to double between 1990 and 2020, the period within which the United Nations declared we must meet the Millennium Development Goals (MDGs) (Johnson, 2009). This trend is expected to lead to a rise in the number of livestock reared worldwide, a factor which threatens to exacerbate climatic imbalances. Already the livestock sector is a source of instability to many ecosystems contributing to global environmental problems (Spore, 2009).

The presence of livestock in the vast majority of the world's ecosystems especially in urban areas constitutes a great hazard. It is often a major source of water pollution (Steinfeld et. al. 2006). Livestock freely roaming around in urban centres can cause traffic accidents and also destroy ornamental plants, water pipes and fences (Foeken, 2006). There is also evidence that many human diseases can be transmitted from livestock to people during production, processing and consumption (FAO, 2001). Major diseases include bovine, tuberculosis, brucellosis and Salmonells (Foeken, 2006). The closeness of human beings to animals in urban areas might facilitate the spread of these diseases.

Greenhouse gas emissions from livestock production and consequent waste are important contributors to climate change (Gerber and Steinfeld, 2008). Glantz et al (2009) observe that the primary sources of methane emission include enteric fermentation from ruminant livestock like cattle, sheep, goat. Large amounts of ammonia are produced when urea and livestock manure break down in water or slurry.

These health and environmental damages caused by livestock are likely to increase if we do not act. This is because demand for milk, meat and eggs is rising rapidly across the developing world especially in urban areas due to increasing urban population. Van de Steeg et al, (2009) note that more research is needed in livestock development and environmental health to ensure that poor farmers are helped to sustain their farming systems over a long term. Inclusion of their (farmers) views and concern is necessary since they are the major stakeholders. This study was therefore designed to ascertain farmer's perception of hazards posed by urban livestock keeping.

Specifically, the study:

(I) ascertained the type of animals kept and the rearing system; 
(II) identified hazards posed by urban livestock keeping; and

(III) determined farmers' perception of control measures.

\section{Methodology}

The study was carried out in Enugu urban. Enugu is the capital and major city in Enugu State of Nigeria. The city is located at latitude $6^{\circ} 27^{\prime}$ north and longitude $7^{\circ} 29^{\prime}$ east off the equator and covers an area of about $73.3 \mathrm{sq} \mathrm{km}$ (Chukwu, 1995).

The population of the study consisted of all livestock keepers in Enugu urban area. Ten wards as delineated by the 1991 census were used for the study. From the ten wards, five wards - Asata, Ogbete, Uwani, Abakpa and GRA were selected using simple random sampling. Fifteen households were purposively selected from each ward based on their active involvement in livestock keeping. This gave a total of 75 households. An interview schedule was used to collect information from heads of households. Percentage and mean score were used to analyze the data.

To determine farmers' perception of measures to control the damages done, a list of possible measures was given to them. They were requested to rate on a 3-point Likert-type scale the extent they perceived the items as control measures to the damages done to urban health and environment. The scale was assigned values as follows; to a great extent $=3$; to a little extent $=2$; to no extent $=1$. A mean score of 2.0 was obtained. Any item with a score of 2.0 and above was regarded as a control measure while items with mean less than 2.0 were not perceived as control measure.

\section{Results and Discussion}

\section{Personal characteristics of the urban livestock keepers}

Table 1 shows that majority (48.0\%) of the respondents fell within the age range of $45-54$, while $19 \%$ were within the age range of $35-44$ years. Those within the age range of $55-64$ years accounted for $21.3 \%$. The mean age of the respondent was 50 years. This implies that most of them were in their active and productive age. This is an advantage for increased utilization of improved technology. Hence any intervention meant for the improvement of urban livestock keeping will be adopted by the farmers. Ani (2007) asserted that innovators are always in their middle age.

A greater proportion (46.7\%) of the respondents was wage employer. Self employed and casual workers were $38.7 \%$ and $7 \%$ of the respondents respectively. Only $8.0 \%$ of the respondents took farming as their main occupation. This shows that most urban farmers practice on part-time basis. This is in line with the finding of Foeken et al., (2000). They found out that one third of urban farmers in Morogoro city of Tanzania were regularly employed. The respondents' therefore acquire income through combination of efforts. 
Entries in Table 1 also indicate that $24 \%$ of the respondents had more than secondary education. About $13 \%$ of them attended but did not complete their primary education while $22.7 \%$ completed their primary education. Thus, majority $(81 \%)$ of the respondents had at least primary education. The fact that most of them were literate is advantageous to the adoption of any innovation meant to improve livestock keeping in the study area. It has been reported that increased farmer education positively influenced adoption of improved practices (Agwu and Anyanwu, 1996). 
TABLE 1

Distribution of respondents according to personal characteristics

\begin{tabular}{lccc}
\hline Personal characteristics & Frequency & $\%$ & M \\
\hline Age & 5 & 6.7 & \\
$25-34$ & 14 & 18.7 & \\
$35-44$ & 36 & 48.0 & 50.0 \\
$45-54$ & 16 & 21.3 & \\
$55-64$ & 4 & 5.3 & \\
$65-74$ & & & \\
Occupational status & 35 & 46.7 & \\
Regularly employed & 5 & 6.7 & \\
Temporal/casual & 29 & 38.7 & \\
Self employed/Trading & 6 & 8.0 & \\
Farming only & & & \\
Level of education & 4 & 5.3 & \\
No. formal education & 10 & 13.3 & \\
Primary school attempted & 17 & 22.7 & \\
Primary school completed & 11 & 14.7 & \\
Secondary school attempted & 15 & 20.0 & \\
Secondary school completed & 18 & 24.0 & \\
Above secondary school & &
\end{tabular}

Source: Survey data, 2010

\section{Types of animal kept and rearing system}

Majority $(66.7 \%)$ of the respondents kept improved chicken. Out of the 75 respondents, $41.3 \%$ and $40 \%$ kept local chicken and goat/sheep respectively. Thirty-two percent kept turkeys while only about $5 \%$ kept pigs (Table 2 ).

The most (53.3\%) commonly practiced rearing system was the intensive system. This was not surprising since majority (66.7\%) kept improved chicken. About $11 \%$ of the respondents practiced free range system while semi-intensive system was adopted by $36 \%$ of the respondents. Olukosi (2005) reported that all over Africa, scavenging chickens in urban areas are known to use free feed resources to produce eggs and meat at almost no cost to their owners. He further suggested that instead of attempting to eliminate the system,, focus should be on optimizing the system so that they should not constitute danger. 
TABLE 2

Distribution of respondents according to animals kept and rearing system

Variables

Types of animals kept ${ }^{\star}$

Improved chicken

66.7

Local chicken

Turkeys

32.0

Rabbits

Goats/sheep

40.0

Pigs

Rearing system

Intensive

Free range

10.7

Semi-intensive

36.0

Source: Survey data, 2010

${ }^{*}$ Multiple response

\section{Awareness and perception of health and environmental hazards posed by urban livestock keeping}

All the $(100 \%)$ respondents were aware that livestock keeping could have a negative effect on urban health and environment. Majority (89.3\%) of the respondents mentioned destruction of crops and filth in urban environment as negative effect of urban livestock keeping. A good number (86.7\%) of the respondents perceived that 'noise' from the livestock can affect health and environment while about $51 \%$ reported that livestock can cause diseases which could be transmitted to human beings. Other damages as indicated by the respondents included: accidents (46.7\%); emission of gases from livestock which cause climate change $(4.0 \%)$ and destruction of water sources $(10.7 \%)$. This implies that majority of them considered livestock as a menace because it generates waste, smell, noise and spread diseases. Only (4.0\%) of them perceived that livestock emit gases which can cause climate change. This implies that majority of urban livestock keepers in the area were not aware of the contribution of livestock to climate change. Only few respondents indicated that livestock could cause depletion of water sources. Gerber and Steinfeld (2008) 
reported that water quality could be affected by livestock as a result of the release of nitrogen, phosphorus and other nutrients into water ways, mainly from intensive livestock.

TABLE 3

Distribution of respondents according to awareness and perception of damage on urban health and environment

\begin{tabular}{lc}
\hline Variables & $\%$ \\
\hline Awareness of damage & 100 \\
Aware & 0 \\
Unaware & 8.0 \\
Perception of type of damage* & 89.3 \\
Livestock keeping can cause erosion & 89.3 \\
Livestock causes filth in environment & 86.7 \\
Bad smell arise from keeping livestock & 50.7 \\
Livestock makes noise & 10.7 \\
Health risk as a result of livestock diseases & 30.7 \\
Livestock depletes water sources & 4.0 \\
It causes destruction of fences & 46.7 \\
It emits gases which can cause climate change & 89.3 \\
Livestocks roaming about can cause accidents & \\
Livestock destroys crops &
\end{tabular}

Source: Survey data, 2010

*Multinle resbonses

Urban livestock keepers in Enugu urban were aware of hazards posed by livestock on health and environment. Though, they indicated effects like diseases, filth, nuisance etc only few of them were aware that livestock can have effect on climate change. It is therefore necessary that extension service and other nongovernmental agencies in urban areas should create awareness of the impact of livestock on climate change. This will enable the keepers to appreciate mitigation strategies to ensure sustainable practices by using environmental - friendly options.

\section{Farmers perception of control measures}

Most of the measures were perceived by them as strategies for controlling the damages. Such measures included: restraining the animals from entering farms (2.85), seeking veterinary services (2.85), cleaning of shades daily to avoid filth (2.84), proper disposal of waste (2.79) and reducing number of animals (2.05) (Table 4). This finding is in line with Foeken (2006) who reported that various ways 
of dealing with problems of livestock keeping include restraining the animals, seeking veterinary services, feeding the animals well to limit noise and ensuring proper disposal of waste.

TABLE 4

Mean distribution of measures used in controlling damages done by livestock keeping

\begin{tabular}{ll}
\hline \multicolumn{1}{c}{ Variables } & Mean \\
\hline Zero grazing & 0.12 \\
Proper disposal of waste & 2.79 \\
Use of manure for cultivation & 2.71 \\
Reducing number of animals & 2.05 \\
Restraining animals & 2.85 \\
Feeding animals well & 2.80 \\
Seeking veterinary services & 2.85 \\
Cleaning sheds daily & 2.84 \\
Provision of extension services & 2.85 \\
\hline
\end{tabular}

\section{Implication for climate change mitigation}

As livestock sector continues to expand, major corrective measures need to be taken to address the environmental impact of livestock production Thus we can identify sustainable interventions - those that provide real incentives for using environmental-friendly options. The challenge is to limit its impact on the environment while satisfying the growing demand for its products (meat, milk and eggs).

Gerber and Steinfeld (2008) assert that emissions from livestock systems can be reduced significantly through technologies, policies and provision of adequate incentives for their implementation. A number of technical options could lessen the impact of intensive livestock production. Conservation agriculture and other forms of resource - preserving technologies can restore important soil habitats and reduce degradation. Intensive livestock production could be located where crop land is within reach, so it can be used for disposal of waste. It is also necessary to improve the management of animal waste (manure and slurry) to reduce methane emission, notably through more efficient conversion into biogas (Spore, 2008). 
The amount of methane produced per unit of animal product can be reduced by giving ruminants better - quality diets (Van de Steeg et al., 2009). This can be achieved with the development of fodder banks, improved pasture species, planted legumes and feed supplements with crop by - products. These practices can increase milk production, improve the efficiency of methane production and help mitigate methane emissions from ruminant production systems. Spore (2008) reports that efforts are underway to improve fodder crops and other feed and make them more digestible so as to reduce flatulence in ruminants.

Another option is to replace low-producing animals with fewer but better-fed animals, thus reducing total emissions while maintaining or increasing the supply of livestock products, (Rota and Thieme, 2009). This will require cross-breeding schemes to produce better species to suit a particular environment. Spore (2008) argues that there is need to use more improved local breeds, which are better adapted to the climate and its variations than imported breeds. This is a strategy that could yield higher productivity per animal for the resources available.

Managing livestock requires a mix of policy, institutional change and technology and investment. Building locally specific capacity that can respond to change is particularly important. Policies and institutional arrangements are essential in mediating how the livestock sector develops in order to reduce health and environmental risks.

\section{References}

Agwu, A. E. and Anyanwu, A. C. (1996). Socio-cultural and environmental constraints in implementing the NALDA programme in Southern Nigeria: A case study of Abia and Enugu State. Journal of Agricultural Technology and Education, Vol. 1, pp. $68-72$.

Ani, A. O. (2007). Agricultural Extension: A pathway for sustainable agricultural development. Apani Publications: Kaduna.

Chukwu, K.E. (1995). The influence of an urbanized catchments area on water disposal; A study of Enugu urban area. M.Sc. Project. Department of Geography, University of Nigeria, Nsukka.

FAO (2006). Adaptation to climate change in agriculture, forestry and fisheries; Perspective framework and priorities. Food and Agricultural Organizations of the United Nations; Rome.

FAO (2001). Urban and peri-urban agriculture. A brief guide for the successful implementation of urban and peri-urban agriculture in developing countries. The special programme for food security. Food and Agricultural Organization; Rome.

Foeken, D., Sofer, M. and Mlozi, M. (2004). Urban agriculture in Tanzania. Issues of sustainability. African study centre: The Netherlands. 
Foeken, D. (2006). Urban agriculture in East Africa as a tool for poverty reduction. A legal and policy dilemma. ASC working paper no. 65. African study center: Leiden.

Gerber, P. J. and Steinfeld, H. (2008). Global environmental consequences of livestock sector's growth. Outlook on Agriculture, Vol. 37 (1): 7 - 13.

Glantz, M. H., Gommes, R. and Ramasamy, S. (2009). Coping with a changing climate: Considerations for adaptation and mitigation in agriculture. Food and Agricultural organization, Rome.

Johnson, N. (2009). Livestock and the millennium development goals (MDGs). Rural 21 Magazine, Vol. 43: 12 - 15.

Olukosi, O. A. (2005). Poultry production. A training manual prepared for one-day training of members of National union of Local Government Employees, Osun State. Obafemi Awolowo University teaching and research farm, lleIfe, Nigeria. November $21^{\text {st }}$.

Rota, A. and Thieme, O. (2009). The livestock challenge. Rural 21 Magazine. Vol. 43: $8-11$.

Steinfeld, H., Gerber, P.; Wassenaar, T., Castel, V. Rosales, M. and de Hann, C. (2006). Livestock long shadow: Environmental Issues and options FAO; Rome.

Spore (2008). Livestock adaptation all round. Spore Magazine Special Issue. August 2008. CTA; $13-14$.

Van de Steeq, J.; Notenbaert, A., Herrero, M. and Thornton,, P. (2009). Livestock and Climate change. Rural 21 Magazine, Vol. 43: 19-21. 